\title{
Tributación y pobreza en Colombia: un análisis desde la evolución del impuesto de renta y el índice de pobreza monetaria ${ }^{1}$
}

\author{
Tania Lorena García Ocampo ${ }^{2}$ \\ Yesica Tatiana Castellanos Sabogal ${ }^{3}$
}

Recibido: 22 de febrero de 2019

Aprobado: 28 de abril de 2019

Clasificación JEL: H23, I32

\section{Resumen}

Los ciudadanos de un país deben aportar a las cargas tributarias para el sostenimiento de su aparato estatal, incluidos aquellos gastos dirigidos al bienestar de la comunidad. En Colombia han sido aprobadas por el Congreso de la Republica cuatro reformas tributarias entre 2010 y 2016, por lo que mediante un análisis de la evolución de los recursos tributarios a partir de estas reformas, sustentado principalmente en el impuesto de renta se procedió a comparar el resultado del recaudo de este impuesto con el

1 Citar como: García, T. L. y Castellanos, Y. T. (2019). Tributación y pobreza en Colombia: un análisis desde la evolución del impuesto de renta y el índice de pobreza monetaria. Revista Activos, 16(30), 79-98. DOI: https://doi.org/10.15332/ 25005278.5061

2 Facultad de Contaduría Pública, Corporación Universitaria Republicana. Bogotá, D.C., Colombia. Línea de investigación: Control, aseguramiento y sostenibilidad organizacional. Correo electrónico: lorenagarcia1901@gmail.com

3 Facultad de Contaduría Pública, Corporación Universitaria Republicana. Bogotá, D.C., Colombia. Línea de investigación: Control, aseguramiento y sostenibilidad organizacional. Correo electrónico: yesicatatiana1224@gmail.com. 
índice de pobreza monetaria (IPM), que a pesar de presentar disminuciones importantes durante el período 2010-2016, sus variaciones porcentuales difirieron del comportamiento de los recursos tributarios, por lo que se generaron interrogantes respecto a sus verdaderos resultados.

Palabras clave: reformas tributarias, ingresos tributarios, pobreza monetaria.

\title{
Taxation and poverty in Colombia: an analysis based on the evolution of the income tax and the monetary poverty index
}

\begin{abstract}
The citizens of a country must contribute to the tax burdens to support their state apparatus, including those expenses aimed at the welfare of the community. In the country, four tax reforms have been approved by the Congress of the Republic between 2010 and 2016, so by an analysis of the evolution of tax resources from these reforms, mainly based on income tax, the result of the collection of this tax is compared with the Monetary Poverty Index, which in spite of presenting significant decreases during the period 2010-2016, its percentage variations differ from the behavior of the tax resources, raising questions about its actual results.
\end{abstract}

Keywords: Tax reforms, tax revenues, monetary poverty. 


\section{Introducción}

El propósito principal de esta investigación fue analizar la evolución del impuesto de renta y su relación con el índice de pobreza monetaria entre los años 2010 y 2016, teniendo en cuenta las reformas tributarias aprobadas en lo que va corrido del milenio, entre las cuales se analizaron las aplicadas en los años 2010 a 2016 y su correspondiente incremento en los ingresos tributarios del Gobierno nacional central y los índices de pobreza del país.

El análisis realizado se dio mediante referentes de la medición de la pobreza y la evolución de la pobreza monetaria durante el período 2010-2016, la relación entre las variables objeto de estudio y finalmente se expresaron unas consideraciones respecto al tema, describiendo las diferentes metodologías utilizadas para la medición de la pobreza que se han aplicado en la población colombiana con el fin de mostrar sus ventajas y desventajas. Se concluyó que una de las más apropiadas es el índice de pobreza multidimensional, el cual está compuesto por una serie de variables tales como educación, salud, vivienda, condiciones de la niñez y trabajo, que logran una medición más profunda en comparación con la que se realiza basada en ingreso monetario. Sin embargo, aunque es un instrumento muy completo, debe responder a ciertas características endógenas propias de la población colombiana como la cultura, la localización geográfica y el contexto social, económico y político.

\section{Marco teórico}

A continuación se explican algunos referentes teóricos y conceptuales relativos a la tributación y la necesidad de contribuir al sostenimiento del Estado y las funciones que este tiene.

En el año 2016 el ministro de Hacienda, Mauricio Cárdenas, se reunió con el Gran Foro Nacional de Reforma Tributaria Estructural donde informó la necesidad de que el Congreso de la Republica aprobara el proyecto de ley para mantener el grado de inversión y el crecimiento económico del 
país, buscando sostener los programas sociales del Gobierno nacional, así como generar empleos y condiciones para el crecimiento de las empresas.

El ministro de Hacienda explicó en su momento que se habían alcanzado grandes logros como la reducción de la pobreza, el incremento de la cobertura en educación y la ampliación de los servicios de salud, pero en ese período el país se encontraba en un instante crítico donde, si no se tomaban las decisiones correctas, se podría correr el riesgo de echar todo a perder; por lo cual se instaló una misión de expertos que terminaron recomendando los cambios estructurales sobre los cuales se debía montar la reforma tributaria en cuestión.

Si la reforma tributaria no se tramitaba en el año 2016 se ponía en peligro el grado de inversión que tiene Colombia y eso significaría que de sus propios recursos, se tendría que destinar más al pago de intereses y menos a la inversión social (Portafolio, 2016).

Los autores clásicos desde el siglo XVIII señalaron los aspectos sustanciales relacionados con los impuestos que deben cobrar las naciones para su subsistencia. Adam Smith (1776) se refirió al tema de la siguiente manera:

Los ingresos privados de los individuos provienen, como ya tuvimos ocasión de observar en la primera parte de esta investigación, de tres fuentes diferentes: rentas, beneficios y salarios. En consecuencia, todo impuesto se ha de pagar, en última instancia, por alguna de estas fuentes de ingreso, o por todas a la vez [...] es necesario dejar establecidas las cuatro máximas siguientes, que comprenden a todos los tributos en general:

I. Los ciudadanos de cualquier Estado deben contribuir al sostenimiento del Gobierno, en cuanto sea posible, en proporción a sus respectivas aptitudes, es decir, en proporción a los ingresos que disfruten bajo la protección estatal.

II. El impuesto que cada individuo está obligado a pagar debe ser cierto y no arbitrario.

III. Todo impuesto debe cobrarse en el tiempo y de la manera que sean más cómodos para el contribuyente. 
IV. Toda contribución debe percibirse de tal forma que haya la menor diferencia posible entre las sumas que salen del bolsillo del contribuyente y las que se ingresan en el Tesoro público, acortando el período de exacción lo más que se pueda (L. 5, cap. 2, parte 2).

David Ricardo (1950) por su parte sostiene sobre el cobro de impuestos:

[...] podrían disminuir los beneficios del capital y del trabajo de cada uno de los afectados que cancelan dichos impuestos. Generalmente esos impuestos recaen sobre el consumidor del producto, aunque no en todos los casos, como es el impuesto sobre la renta, que recaería exclusivamente sobre el propietario, quien no podría en modo alguno, trasladarlo a su arrendatario (Ricardo, p. 205).

\section{Marco normativo}

En un país nace la necesidad de crear o modificar las reformas tributarias con el fin de lograr un recaudo fiscal significativo para suplir necesidades de carácter social y económico, ya que muchas veces el gasto que tiene cada nación supera el valor de los ingresos que recibe y empieza a incrementar su deuda. La Constitución Política de Colombia le otorgó al Congreso de la República el poder tributario para establecer los tributos, modificarlos o derogar aquellos existentes.

En el caso de los impuestos territoriales, quienes tienen el poder de reglamentar estos tributos son las asambleas departamentales, a través de ordenanzas y los concejos municipales, por medio de acuerdos.

En los impuestos nacionales la entidad que está encargada de administrar y recaudar los tributos es la Dirección de Impuestos y Aduanas Nacionales (DIAN) y todo el dinero que recauda esta entidad por los diferentes tributos que tiene Colombia entran a formar parte del presupuesto general de la nación, que es el dinero con el que cuenta el Estado para financiar los gastos, las inversiones, las obras públicas y la prestación de servicios (La Nación, 2016). 
A continuación, se realiza un breve recuento de los cambios introducidos en las respectivas leyes tributarias:

\section{Ley 1430, reforma tributaria del 2010}

- Desde el año 2011 se eliminó la deducción especial por inversión en activos fijos reales productivos.

- La nueva ley establece que las sociedades de hogares comunitarios y hogares infantiles y las asociaciones de adultos mayores autorizados por el Instituto Colombiano de Bienestar Familiar, son no contribuyentes del impuesto de renta.

- Con esta normativa quedaron sometidos a retención en la fuente los ingresos por concepto de exportación de hidrocarburos y demás productos mineros.

- Retención en la fuente a través de las entidades financieras, con el fin de asegurar el control y la eficiencia en el recaudo de los impuestos nacionales (Accounter, 2010).

\section{Ley 1607, reforma tributaria del 2012}

- Se reduce la tarifa del impuesto de renta del 33 al $25 \%$ a partir del año 2013.

- La creación del impuesto sobre la renta para la equidad (CREE) se hizo con el fin de destinar los recursos recibidos por este impuesto a la financiación del Sistema de Seguridad Social en Salud, en inversión social con el fin de beneficiar a la población usuaria más necesitada y que estuviera a cargo del Servicio Nacional de Aprendizaje (SENA) y del Instituto Colombiano de Bienestar Familiar (ICBF).

- La base gravable del CREE era similar a la del impuesto de renta pero no se podían deducir las donaciones a entidades calificadas, ni las pérdidas fiscales.

- Las entidades sin ánimo de lucro no fueron sujetos pasivos del impuesto sobre la renta para la equidad (CREE) y siguieron obligadas a realizar los aportes parafiscales.

- Exoneración, aportes parafiscales y de salud: estarán exoneradas del pago de los aportes parafiscales a favor del Servicio Nacional de Aprendizaje (SENA) y del Instituto Colombiano de Bienestar Familiar (ICBF), las sociedades y personas jurídicas contribuyentes y declarantes del impuesto de renta para la equidad 
(CREE), correspondientes a los trabajadores que devenguen individualmente hasta diez (10) salarios mínimos legales vigentes.

- La reforma tributaria del año 2012 estableció dos nuevos sistemas presuntivos para la determinación de la base gravable del impuesto sobre la renta y complementarios, los cuales fueron conocidos como: impuesto mínimo alternativo nacional (IMAN) e impuesto mínimo alternativo simple (IMAS), los cuales eran aplicados dependiendo la clasificación de persona natural que reciba el contribuyente, ya sea como empleado o trabajador por cuenta propia (Comunidad Contable, 2012).

\section{Ley 1739 de 2014}

- Creación del impuesto a la riqueza: este impuesto estaría vigente desde el año 2015 y hasta el año 2018 y quienes estaría a cargo de presentarlo serían las personas naturales, jurídicas y sociedades de hecho contribuyentes del impuesto sobre la renta y complementarios.

- Se fija la tarifa del CREE en un $9 \%$, y las pérdidas fiscales en que incurran los contribuyentes de este impuesto a partir del año gravable 2015 podrán compensarse en este impuesto de conformidad con lo establecido en el artículo 147 del ET.

- Se crea una sobretasa al impuesto sobre la renta para la equidad (CREE) para los períodos gravables 2015 al 2018; esta cuando el valor del impuesto supere los $\$ 800 ’ 000.000$ y deberá pagarse en dos cuotas anuales en los plazos que fije el reglamento.

- Los recursos que se recauden por medio de la sobretasa del impuesto sobre la renta para la equidad (CREE), no tienen una destinación específica pero formarán parte del Fondo Especial sin personería -Fondo CREE- y estarán en caja con los demás ingresos corrientes de la nación (Comunidad Contable, 2014).

\section{Ley 1819 de 2016}

- Impuesto sobre la renta de personas naturales: depuración cedular. La depuración de estas rentas corresponde a cada cédula y se realizará de manera independiente para las siguientes cédulas: 
- Rentas de trabajo: se consideran rentas de trabajo las obtenidas por personas naturales por concepto de salarios, comisiones, prestaciones sociales, viáticos, gastos de representación y honorarios.

- Rentas de pensiones: son ingresos de estas cédulas las pensiones de jubilación, invalidez, vejez, de sobrevivientes y de riesgos laborales.

- Rentas de capital: son ingresos de esta cédula los obtenidos por concepto de intereses, rendimientos financieros, arrendamientos, regalías y explotación de la propiedad intelectual.

- Rentas no laborales: se consideran ingresos de las rentas no laborales todos aquellos que no se clasifiquen expresamente en ninguna de las otras cédulas.

- Rentas de dividendos y participaciones: son ingresos de esta cédula los recibidos por concepto de dividendos y participaciones y constituyen renta gravable en cabeza de los socios, accionista, asociados y similares.

- Impuesto sobre la renta para personas jurídicas: las personas jurídicas dejarán de pagar el impuesto a la riqueza, el CREE, la sobretasa del CREE y solo pagarán renta la tarifa general del impuesto sobre la renta para las sociedades nacionales y asimiladas y las personas jurídicas extranjeras o sin residencia obligadas a presentar la declaración anual del impuesto sobre la renta y complementarios. Esta tarifa será del $34 \%$ para el año 2017 y del $33 \%$ en el año 2018.

- Se crea para 2017 y 2018 una sobretasa del impuesto sobre la renta para contribuyentes que liquiden una base superior a $\$ 800^{\prime} 000.000$

- Creación del monotributo: la creación de este impuesto busca formalizar a los pequeños comerciantes, solamente personas naturales quienes se beneficiarán con un ahorro a la vejez y cobertura en riesgos laborales y este impuesto se liquidará sobre el $1 \%$ de sus ingresos (Actualícese, 2016).

\section{Marco metodológico}

El presente estudio es de tipo descriptivo y analítico con un enfoque metodológico cuantitativo, mediante datos estadísticos brindados por el Departamento Nacional de Estadística (DANE) junto con el Ministerio de 
Hacienda y Crédito Público, en lo que tiene que ver con la recolección y procesamiento de información estadística utilizada para recoger evidencia real sobre el comportamiento que han tenido los recursos tributarios y los indicadores de pobreza con el propósito de ser contrastados.

\section{Desarrollo del tema}

La pobreza se examina mediante dos índices presentados por el Dane, el índice de necesidades básicas insatisfechas (NBI) y el índice de pobreza multidimensional (IPM), dichos índices reflejan el porcentaje de población pobre en Colombia y son obtenidos a través de encuestas realizadas por el mismo Dane, donde el índice de NBI es obtenido a partir de la Encuesta Nacional de Calidad de Vida (ECV) y la Encuesta Continua de Hogares (ECH), y el IPM es obtenido a partir de la Encuesta Nacional de Calidad de Vida (ENCV) y enlazado con el índice de pobreza monetaria a partir de la Gran Encuesta Integrada de Hogares (GEIH). Cabe aclarar que la pobreza durante el período 2002-2005 se calculó a través de la Encuesta Continua de Hogares, y de 2008 a 2015 se cambió la metodología y se viene realizando con base en la Gran Encuesta Integrada de Hogares. Para los años 2006 y 2007 no se presentan cifras de pobreza, debido a que no se pudo realizar el empalme de las metodologías utilizadas por el Dane para la medición de la pobreza en Colombia.

\section{Necesidades básicas insatisfechas (NBI)}

La metodología de NBI busca determinar, con ayuda de algunos indicadores simples, si las necesidades básicas de la población se encuentran cubiertas. Los grupos que no alcancen un umbral mínimo fijado son clasificados como pobres. Los indicadores simples seleccionados son: viviendas inadecuadas, viviendas con hacinamiento crítico, viviendas con servicios inadecuados, viviendas con alta dependencia económica y viviendas con niños en edad escolar que no asisten a la escuela (DANE, NBI). 
Tabla 1. Medición NBI

\begin{tabular}{l|l}
\hline $\begin{array}{l}\text { Viviendas } \\
\text { inadecuadas }\end{array}$ & $\begin{array}{l}\text { Este indicador expresa las características físicas de viviendas } \\
\text { consideradas impropias para el alojamiento humano. Se clasi- } \\
\text { fican en esta situación separadamente las viviendas de las } \\
\text { cabeceras municipales y las del resto. }\end{array}$ \\
\hline $\begin{array}{l}\text { Viviendas con haci- } \\
\text { namiento crítico }\end{array}$ & $\begin{array}{l}\text { Con este indicador se busca captar los niveles críticos de } \\
\text { ocupación de los recursos de la vivienda por el grupo que } \\
\text { la habita. Se consideran en esta situación las viviendas con } \\
\text { más de tres personas por cuarto (excluyendo cocina, baño y } \\
\text { garaje). }\end{array}$ \\
\hline $\begin{array}{l}\text { Viviendas con ser- } \\
\text { vicios inadecuados }\end{array}$ & $\begin{array}{l}\text { Este indicador expresa en forma más directa el no acceso } \\
\text { a condiciones vitales y sanitarias mínimas. Se distingue, } \\
\text { igualmente, la condición de las cabeceras y las del resto. En } \\
\text { cabeceras, comprende las viviendas sin sanitario o que care- } \\
\text { ciendo de acueducto se provean de agua en río, nacimiento } \\
\text { o de la lluvia. En el resto, dadas las condiciones del medio } \\
\text { rural, se incluyen las viviendas que carezcan de sanitario y } \\
\text { acueducto y que se aprovisionen de agua en río, nacimiento } \\
\text { o de la lluvia. }\end{array}$ \\
\hline $\begin{array}{l}\text { Viviendas con } \\
\text { alta dependencia } \\
\text { económica }\end{array}$ & $\begin{array}{l}\text { Es un indicador indirecto sobre los niveles de ingreso. Se } \\
\text { clasifican aquí las viviendas en los cuales haya más de tres } \\
\text { personas por miembro ocupado y el jefe tenga, como máxi- } \\
\text { mo, dos años de educación primaria aprobados. }\end{array}$ \\
\hline $\begin{array}{l}\text { Viviendas con ni- } \\
\text { nues en edad escolar asisten a la } \\
\text { escuela }\end{array}$ & $\begin{array}{l}\text { Mide la satisfacción de necesidades educativas mínimas para } \\
\text { la población infantil. Considera las viviendas con por lo me- } \\
\text { nos un niño mayor de 6 años y menor de 12, pariente del jefe } \\
\text { del hogar y que no asista a un centro de educación formal. }\end{array}$ \\
\hline
\end{tabular}

Fuente: elaboración propia con base en información del Dane.

Para estimar la magnitud de la pobreza en relación con la población, se consideró que las personas que habitaban en viviendas con NBI o en miseria se encontraban en las mismas condiciones de su respectiva vivienda. EL Dane desarrolló estudios de nuevos indicadores que permiten análisis más elaborados para el seguimiento adecuado del desarrollo de las metas del milenio. 


\section{Índice de pobreza multidimensional (IPM)}

El IPM surge como respuesta a la necesidad de contar con una medida de pobreza con el propósito de hacer diseño y seguimiento a la política pública. Así mismo, la posibilidad de realizar un análisis profundo de múltiples dimensiones de la pobreza diferente al ingreso, hizo del IPM un instrumento útil para reflejar las privaciones que debe enfrentar un hogar en Colombia y, por ende, ideal para el seguimiento de la política pública. De igual manera, el IPM es una investigación que permite recoger información sobre diferentes dimensiones y variables del bienestar de los hogares. Se incluyen variables relacionadas con las condiciones educativas del hogar, las condiciones de la niñez y juventud, trabajo, salud y acceso a servicios públicos domiciliarios y condiciones de la vivienda (DANE, 2016).

Figura 1. Pobreza multidimensional, período 2010-2016

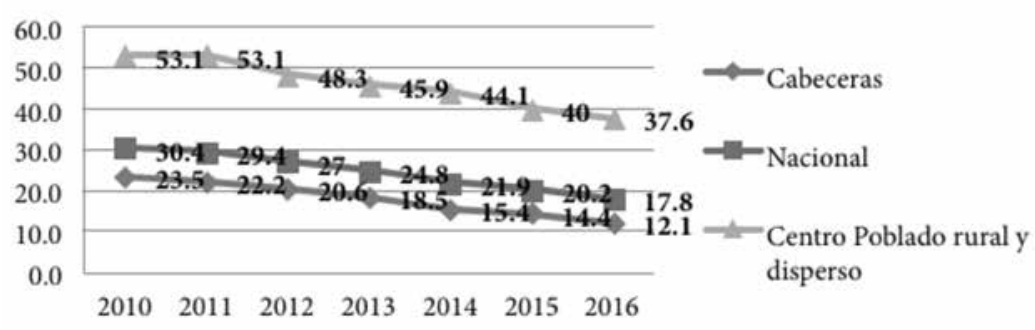

Fuente: elaboración propia con base en información del Dane.

El índice de pobreza multidimensional (IPM) mide el entorno de una familia donde se incluye la educación para los hijos, el trabajo infantil, el desempleo, el empleo informal, el acceso al sistema de salud, las condicione de vivienda en las que viven y con esta información obtenida se busca mejorar los alcances de las políticas sociales ya que muestra en cuáles departamentos, ciudades y municipios los servicios sociales son más o menos deficientes. El IPM también mide los ingresos que reciben las familias, así como los consumos de la canasta familiar (DANE, 2016). 
Para 2016, el porcentaje de personas en situación de pobreza multidimensional fue de $17.8 \%$; en las cabeceras de $12.1 \%$ y en los centros poblados y rural disperso de $37.6 \%$. En 2016, el porcentaje de personas en situación de pobreza multidimensional en los centros poblados y rural disperso fue 3.1 veces el de las cabeceras. Entre 2010 y 2016, la reducción de la pobreza multidimensional para el total nacional fue de 12.6 puntos porcentuales, en las cabeceras fue de 11.4 puntos porcentuales y en los centros poblados y rural disperso de 15.5 puntos porcentuales.

Figura 2. Incidencia ajustada de la pobreza multidimensional por regiones, período 2010-2016

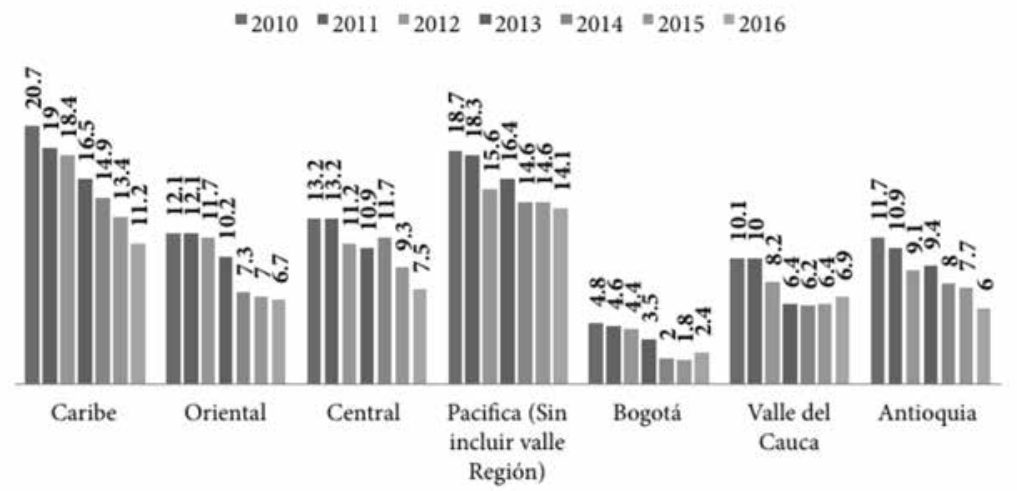

Fuente: elaboración propia con base en información del Dane. Cálculos con base en la encuesta de calidad de vida (ECV) 2010-2016.

Se presenta una incidencia ajustada incluyendo la proporción de privaciones entre los pobres, esta refleja cambios cuando una persona pobre cambia su porcentaje de privaciones. Así, para evaluar cómo contribuye la privación en una variable a la pobreza multidimensional, es útil analizar la descomposición de esta última medida en cada una de las variables que hacen parte del índice (DANE 2016, p. 34).

En la Figura 2, durante el período analizado correspondiente a los años 2010 a 2016, la incidencia ajustada pasó de 20.7 \% a $11.2 \%$ en la región Caribe; de $12.1 \%$ a $6.7 \%$ en la región Oriental; de $13.2 \%$ a $7.5 \%$ en la 
región Central; de 18.7 \% a $14.1 \%$ en la región Pacífica (sin incluir Valle del Cauca); de $4.8 \%$ a $2.4 \%$ en Bogotá; de $101 \%$ a $4.9 \%$ en Valle del Cauca y de $11.7 \%$ a $6.0 \%$ en Antioquia.

\section{Pobreza monetaria}

Figura 3. Evolución pobreza monetaria, total nacional, período 2010-2016

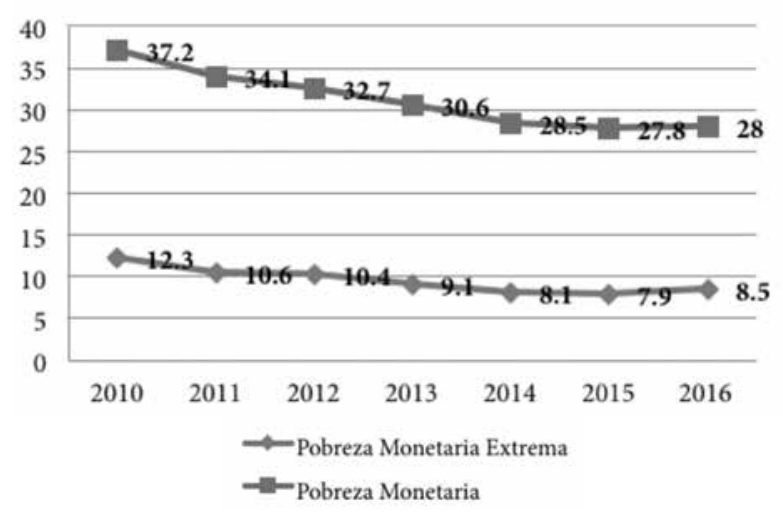

Fuente: elaboración propia con base en información del DANE.

Como se evidencia en la Figura 3, los índices de pobreza han venido disminuyendo de manera paulatina durante los años de análisis, logrando una reducción de 9.2 puntos porcentuales para la pobreza monetaria nacional y de 3.8 para la pobreza monetaria extrema nacional.

Una vez se presentó el cambio de metodología de medición de la pobreza en Colombia, efectivamente la reducción de la pobreza monetaria pasó de 12.5 a 7.7 y para la pobreza extrema de 6.5 a 1.3 . La pobreza multidimensional en Colombia ha mantenido una tendencia decreciente desde el 2010: pasó de $30.4 \%$ al inicio de la década a $17.8 \%$ en 2016. Esto significa que el país pasó de tener 13719000 personas en condición de pobreza multidimensional en 2010 a 8586000 en 2016, lo que equivale a una reducción de 5133000 personas en ese período. Tanto la pobreza monetaria como la pobreza monetaria extrema mantuvieron una tendencia 
decreciente hasta 2015, para el 2016 se presentan leves incrementos en las dos variables.

La hacienda pública y la política monetaria son los principales instrumentos de intervención con que cuenta un Gobierno para impulsar la economía e incidir en el bienestar de la población. La reforma tributaria, según lo argumentó la administración del presidente Santos (2010-2014), tiene como objetivos la generación del empleo (crear entre 850000 a 1000 000 de nuevos empleos), la disminución de la pobreza, la reducción de la desigualdad y un sistema tributario que sea progresivo; sin embargo, la reforma tributaria es regresiva. Con el pretexto de incentivar la inversión y generar empleo formal se disminuyeron los impuestos directos y se aumentaron los impuestos indirectos.

Teniendo en cuenta lo anterior, es importante resaltar que con el cambio de metodología se presentan diferencias en la comparación de las variables de la Encuesta Continua de Hogares y la Gran Encuesta Integrada de Hogares, pues al agregar nuevos elementos y al aumentar la cobertura nacional se perciben cambios a la hora de presentar las cifras de pobreza en Colombia.

Figura 4. Pobreza monetaria, cabeceras, período 2010-2016

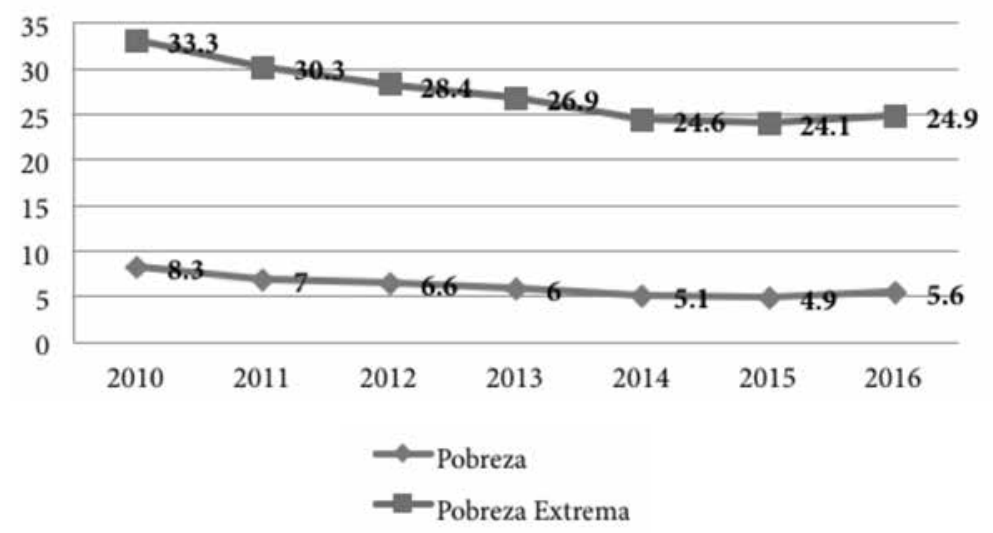

Fuente: elaboración propia con base en información del DANE. 
Como se observa en la Figura 4, se pueden resaltar las variaciones que se presentaron en el período analizado, percibiendo la notable disminución entre pobreza extrema, la cual disminuyó en 8.4 puntos porcentuales, y pobreza, 2.7 puntos porcentuales, reflejando un descenso en el período 2010-2016.

En 2016 el $28.0 \%$ de los colombianos estaba en condición de pobreza monetaria, lo cual representa una variación de 0.2 puntos porcentuales frente a 2015 , cuando fue de $27.8 \%$. La pobreza en las cabeceras municipales pasó de $24.1 \%$ en 2015 a $24.9 \%$ en 2016, cambio equivalente a 0.8 puntos porcentuales. La pobreza en los centros poblados y zonas rurales dispersas fue de $38.6 \%$, lo cual representa una disminución de 1.7 puntos porcentuales, frente a 2015 cuando fue de $40.3 \%$. En 2016 el $8.5 \%$ del total de la población estaba en condición de pobreza extrema. En las cabeceras municipales pasó de $7.9 \%$ en 2015 a $8.6 \%$ en 2016 y en los centros poblados de $18.0 \%$ en 2015 a $18.1 \%$ en 2016. Los resultados de la pobreza monetaria y la pobreza monetaria extrema se explican en gran parte por el comportamiento de la inflación en el año 2016 (DANE, 2016, p. 13).

Según el autor Eduardo Bolaños, en Colombia se considera que las personas son pobres cuando el ingreso mensual no supera $\$ 241673$, lo que quiere decir que una familia de 4 personas es considerada pobre si su ingreso mensual es inferior a $\$ 966692$, pero la diferencia está en que el salario mínimo ha estado siempre por debajo de este valor lo que significa que no es suficiente para satisfacer las necesidades básicas de un hogar en Colombia.

En el país son consideradas en situación de pobreza extrema aquellas personas cuyo ingreso mensual no supera \$114 692 según el DANE, pero este ingreso solo satisface las necesidades básicas de una sola persona que sería lo suficiente para sobrevivir. 


\section{Relación ingresos tributarios (impuesto de renta) y pobreza monetaria}

En la Tabla 2 se muestra el recaudo por impuesto de renta durante el período 2010-2016.

Tabla 2. Impuesto de renta miles de millones de pesos, período 2010-2016

\begin{tabular}{l|c|c|c|c|c|c|c}
\hline Año & 2010 & 2011 & 2012 & 2013 & 2014 & 2015 & 2016 \\
\hline $\begin{array}{l}\text { Impuesto } \\
\text { de renta }\end{array}$ & $26.218,9$ & 33.453 & $43.671,9$ & $44.803,5$ & $37.621,9$ & $38.730,7$ & $40.216,0$ \\
\hline
\end{tabular}

Fuente: DGPM - Ministerio de Hacienda y Crédito Público.

Estas cifras se procedieron a deflactarse tomando como año base el año 2010 para observar cómo fue su evolución.

Tabla 3. Recaudo de impuesto de renta precios a 2010

\begin{tabular}{l|c}
\hline Año & Recaudo impuesto de renta \\
\hline 2010 & 26.2 \\
\hline 2011 & 31.3 \\
\hline 2012 & 39.7 \\
\hline 2013 & 39.9 \\
\hline 2014 & 32.8 \\
\hline 2015 & 33.0 \\
\hline 2016 & 32.4 \\
\hline
\end{tabular}

Fuente: elaboración propia con base en información del Ministerio de Hacienda y Crédito Público, Balance fiscal GNC, DGPN.

Una vez revisada la evolución de los ingresos tributarios de acuerdo con las diferentes reformas tributarias y los índices de pobreza, se procedió a identificar la relación existente entre las variables objeto de estudio, las cuales se compilaron en la Figura 5. 
Figura 5. Relación ingresos fiscales (impuesto de renta) y pobreza monetaria
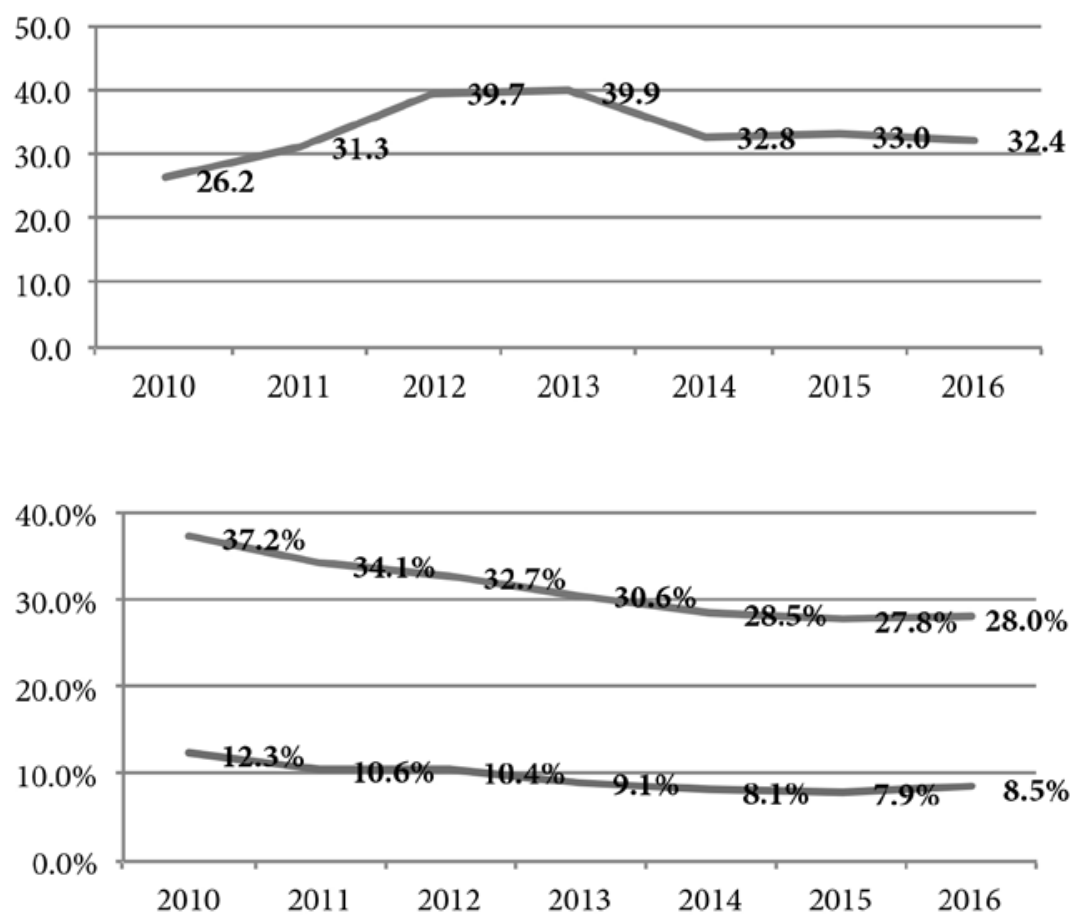

Pobreza Monetaria $\quad$ Pobreza Monetaria Extrema

Fuente: elaboración propia con base en información del Ministerio de Hacienda y Crédito Público, balance fiscal GNC (realizado con datos deflactado del año 2010).

Como se observa en la Figura 5, las variaciones porcentuales de los índices de pobreza difirieron del comportamiento de los recursos tributarios, por cuanto era de esperarse que a mayores ingresos recibidos por el Estado se mejoraran los indicadores sociales sustancialmente. En este caso, para los años 2011 y 2012 cuando se dio un aumento de $26.8 \%$ en el recaudo del impuesto de renta, el índice de pobreza monetaria disminuyó en un $4.1 \%$ y la pobreza monetaria extrema lo hizo en un $1.8 \%$, mientras que en los años 2013 y 2014, cuando cayó el recaudo del impuesto de renta en 
un $17.8 \%$, el índice de pobreza monetaria se redujo en $6.9 \%$, en tanto la pobreza extrema lo hizo en un $11 \%$. Lo anterior resulta ser contradictorio por cuanto no se ve reflejado el mayor o menor recaudo tributario (impuesto de renta) en los índices de pobreza.

\section{Consideraciones}

Según el análisis de las variables durante el período analizado, se pudo establecer que los índices de pobreza no se sustentan en mayores recaudos del Gobierno nacional central ni en relación con las reformas tributarias.

El cambio de metodología de medición de la pobreza tiene relación con la reducción de la misma, lo cual genera muchas incógnitas por cuanto la desigualdad y las estructuras fiscales regresivas constituyen un grave problema, en la medida que comprometen seriamente la asignación de recursos para el desarrollo.

Las variaciones porcentuales de los índices de pobreza difieren del comportamiento de los recaudos tributarios, siendo más notorio el de pobreza monetaria extrema por cuanto su reducción es mínima cuando aumenta el recaudo tributario y es mayor cuando este se reduce. Por su parte, el índice de pobreza monetaria presenta reducciones mínimas con grandes incrementos en los recursos tributarios en algunos años y en otros muestran una relación directa. En este sentido, surgen nuevos interrogantes en cuanto a las cifras de pobreza, ya que estas no se encuentran soportadas en la realidad que se afronta.

\section{Referencias}

Accounter. (29 de diciembre de 2010). Ley 1430. Por medio de la cual se dictan normas tributarias de control y para la competitividad. Recuperado de http:// www.accounter.co/normatividad/leyes/ley-1430-por-medio-de-la-cualse-dictan-normas-tributarias-de-control-y-para-la-competitividad.html, recuperado el 28.03.2018. 
Actualícese. (29 de diciembre de 2016). Reforma tributaria. Recuperado de https:// actualicese.com/normatividad/2016/12/29/ley-1819-de-29-12-2016-reformatributaria/, el 03.03.2018.

Comunidad Contable. (24 de diciembre de 2014). Nueva reforma tributaria. Ley 1739 de 2014. Recuperado de http://www.comunidadcontable.com/ BancoNorma/N/nueva_reforma_tributaria_ley_1739_del_2014/nueva_reforma_tributaria_ley_1739_del_2014.asp, recuperado el 18.02.2018.

Comunidad Contable. (29 de diciembre de 2012). Los cinco puntos más relevantes de la reforma tributaria. Recuperado de http://www.comunidadcontable.com/ BancoConocimiento/N/noti-121226-02(los_cinco_puntos_mas_relevantes_de_la_reforma_tributaria)/noti-121226-02(los_cinco_puntos_mas_relevantes_de_la_reforma_tributaria).asp?Miga $=1 \&$ IDobjetose $=12950 \&$ Cod Seccion=106, recuperado el 22-03-2018.

Departamento Administrativo Nacional de Estadística - DANE. (2014). Encuesta Continua de Hogares. (2002-2005), Gran Encuesta Integrada de Hogares (2008-2014). Recuperado de https://formularios.dane.gov.co/Anda_4_1/ index.php/catalog/206, recuperado el 18-10-2018.

Departamento Administrativo Nacional de Estadística - DANE. (2016). Colombia - Índice de Pobreza Multidimensional (IPM) 2016. Recuperado de https:// formularios.dane.gov.co/Anda_4_1/index.php/catalog/455, recuperado el 10-10-2017.

Departamento Administrativo Nacional de Estadística - DANE. (2016). Colombia - Medición de Pobreza Monetaria y Desigualdad. Recuperado de http:// formularios.dane.gov.co/Anda_4_1/index.php/catalog/410/get_microdata

Departamento Administrativo Nacional de Estadística - DANE. Necesidades Básicas Insatisfechas (NBI). Recuperado de https://www.dane.gov.co/index. php/estadisticas-por-tema/pobreza-y-condiciones-de-vida/necesidadesbasicas-insatisfechas-nbi, el 10.10.2017.

La Nación. (6 de marzo de 2016). ¿Para qué se usa el dinero de los impuestos? Periódico La Nación. Recuperado de https://www.lanacion.com.ar/1876949para-que-se-usa-el-dinero-de-los-impuestos, recuperado el 28.03.2018.

Ministerio de Hacienda y Crédito Público. (25 de junio de 2018). Balance fiscal GNC. DGPM. Recuperado de http://www.minhacienda.gov.co/ HomeMinhacienda/faces/oracle/webcenter/portalapp/pages/politicafiscal/ 
GobiernoNacionalCentralGNC.jspx?_afrLoop $=622956396968533 \&$ _ afrWindowMode $=0 \&$ \&_afrWindowId=43ny8wu1e_1\#!\%40\%40\%3F_ afrWindowId\%3D43ny8wu1e_1\%26_afrLoop\%3D622956396968533\%26_ afrWindowMode\%3D0\%26_adf.ctrl-state\%3D43ny8wu1e_45

Portafolio. (4 de noviembre de 2016). El llamado del ministro de Hacienda al Congreso: "la reforma tributaria es necesaria ahora". Diario Portafolio. Recuperado de http://www.portafolio.co/economia/por-que-colombianecesita-la-reforma-tributaria-501457, recuperado el 30 de abril de 2018

Ricardo, D. (1950). Principios de economía política y tributación. Londres, Reino Unido: Cambridge University Press.

Smith, A. (1776). La riqueza de las Naciones Libro V capítulo II. Madrid, España: Nueva Alianza. 